\title{
Adsorptive Stripping Voltammetric Determination of Venlafaxine in Urine with a Mercury Film Microelectrode
}

\author{
Simone Morais, ${ }^{*}$ Christine P. M. C. A. Ryckaert, \\ and Cristina Delerue-Matos \\ CEQUP/Instituto Superior de Engenharia do \\ Instituto Polite' cnico do Porto, Departamento de \\ Engenharia Quí mica, Porto, Portugal
}

\section{ABSTRACT}

An adsorptive stripping voltammetric procedure for the determina-tion of the antidepressant venlafaxine in urine using a mercury film microelectrode was developed. The method is based on controlled adsorptive accumulation of the drug at the potential of $-1.00 \mathrm{~V}(\mathrm{vs} . \mathrm{Ag} / \mathrm{AgCl})$ in the presence of $1.25 \times 10^{-2} \mathrm{~mol} \mathrm{~L}^{-1}$ borate buffer ( $\mathrm{pH} 8.7$ ). Urine samples were analyzed directly after performing a ten-fold dilution with the supporting electrolyte but without other pretreatment. The limit of detection obtained for a $30 \mathrm{~s}$ collection time was $0.693 \times 10^{-6} \mathrm{~mol}$ $\mathrm{L}^{-1}$. Recovery experiments gave good results at the $10^{-6} \mathrm{~mol} \mathrm{~L}^{-1}$ level (bias less $5 \%$ were obtained).

Key Words: Venlafaxine; Mercury film microelectrode; Adsorptive stripping voltammetry; Urine.

\section{INTRODUCTION}

Venlafaxine (1-[2-(Dimethylamino)-1-(methoxyphenyl)ethyl]cyclo- hexanol hydrochloride; V) is a novel nontricyclic antidepressant available in the European market since 1997. V, like the tricyclic antidepressants, imparts antidepressant effects by inhibiting the neuronal uptake of norepinephrine, serotonin, and to a lesser extent dopamine. ${ }^{[1]}$ It lacks monoamine oxidase inhibitory activity and, more importantly, lacks the adverse effect profile of tricyclic antidepres- sants. ${ }^{[1]}$ Clinical manifestations of toxicity and untoward side effects include anxiety, nervousness, and insomnia. ${ }^{[2]}$ Increasingly, the monitoring of drugs in biological fluids, such as plasma and urine, is being considered a rational approach for the correct management of patient therapy and for minimizing side effects. Accordingly, methods involving, exclusively, extractions with organic solvents, followed by assay by gas chromatography ${ }^{[2]}$ and high performance liquid chromatography ${ }^{[3]}$ have been reported for the determination of this drug in biological fluids. The polarographic behavior of $\mathrm{V}$ has been studied previously by one of us and applied successfully to the analysis of two pharmaceutical formulations. ${ }^{[4]}$ Several authors have claimed and proved that the use of mercury film electrodes is analytically advantageous over the use of hanging mercury drop electrode. ${ }^{[5-6]}$ Furthermore, mercury film electrodes, principally if microelectrodes are utilized, are, environmentally, much less aggressive since lower quantities of contaminated effluent are produced.

The aim of the present study was to investigate the adsorptive behav-ior of $\mathrm{V}$ in a biological fluid, urine, using a mercury film microelectrode (MFM) and to develop a simple and accurate stripping voltammetric procedure for its routine therapeutic or toxic dose monitoring in urine. Adsorptive 
voltammetry, which has been proven suitable for the quanti- fication of a large variety of biologically significant organic molecules, ${ }^{[7-8]}$ when coupled with the inherent properties of microelectrodes ${ }^{[9-}$ ${ }^{10]}$ has shown to be a reliable and promising technique. ${ }^{[11-13]}$ 


\section{EXPERIMENTAL}

\section{Reagents}

The mercury deposition solution was a deoxygenated solution containing $1.00 \mathrm{~mol} \mathrm{~L}^{-1}$ potassium nitrate plus $5.70 \times 10^{-3} \mathrm{~mol} \mathrm{~L}^{-1}$ mercury (II) nitrate and $0.500 \%$ (V/V) nitric acid (65\%). ${ }^{[14]}$

Stock standard solutions of $\mathrm{V}$ hydrochloride (Effexor, Wyeth-Ayerst Laboratories) of $1.59 \times 10^{-3} \mathrm{~mol}$ $\mathrm{L}^{-1}$ and $3.29 \times 10^{-3} \mathrm{~mol} \mathrm{~L}^{-1}$ were prepared by dissolving the exact weight of the active component in deionized and triply distilled water each week. Solutions were stored at $4^{\circ} \mathrm{C}$ and protected from light.

The supporting electrolyte was borate buffer, $\mathrm{pH}^{1 / 4} 8.7\left(1.25 \times 10^{-2} \mathrm{~mol} \mathrm{~L}^{-1}\right.$ sodium tetraborate decahydrate and $1.20 \times 10^{-2} \mathrm{~mol} \mathrm{~L}^{-1}$ hydrochloride acid). For $\mathrm{pH}$ studies, the Britton-Robinson buffer ${ }^{[15]}$ was prepared with $4.00 \times 10^{-2} \mathrm{~mol} \mathrm{~L}^{-1}$ acetic acid, $4.00 \times 10^{-2} \mathrm{~mol} \mathrm{~L}^{-1}$ phosphoric acid and $4.00 \times 10^{-2} \mathrm{~mol} \mathrm{~L}-1$ boric acid. Required $\mathrm{pH}$ values were adjusted by addition of $0.500 \mathrm{~mol} \mathrm{~L}^{-1}$ or $5.00 \mathrm{~mol} \mathrm{~L}^{-1}$ hydrochloride acid or sodium hydroxide. All reagents used were of analytical reagent grade (Merck). Deionized and triply distilled water was used for preparing all solutions.

\section{Apparatus}

An AUTOLAB potentiostat/galvanostat model PSTAT 10 coupled with an ECD Module from EcoChemie controlled by a PC, through the Model GPES3 software, was used for all electrochemical measurements. The Voltammetric studies were performed with a working MFM using an $\mathrm{Ag} / \mathrm{AgCl} / 3.00 \mathrm{~mol}$ $\mathrm{L}^{-1}$ potassium chloride reference electrode (to which all the potential values are referred) and a cylindrical carbon counter electrode. Electrical connections were made with low noise coaxial cables and the electrochemical system was placed inside a thick-walled aluminum Faraday cage.

\section{Procedures}

In the beginning of each working day, a gold microelectrode (radius $1 / 412.5 \mathrm{~mm}$; purchased from the Department of Chemistry of the University of Southampton) was polished with $0.015 \mathrm{~mm}$ alumina, and rinsed abundantly with deionized water until a perfect cyclic steady-state 
(sigmoidal) voltammogram was obtained in a solution containing $0.100 \mathrm{~mol} \mathrm{~L}^{-1}$ of iron (III)/iron (II) in $1.00 \mathrm{~mol} \mathrm{~L}^{-1}$ of potassium nitrate aqueous solution. ${ }^{[16]}$

Then, the working MFM was prepared by electrodeposition of a mercury film onto the gold microdisk by the application of a constant potential of $0.00 \mathrm{~V}$ during a deposition time of $60 \mathrm{~s}$ from the mercury deposition solution. ${ }^{[14]}$ The MFM was removed, rinsed with deionized and triply distilled water and inserted in the solution to be analyzed.

Urine samples were obtained from healthy volunteers and were spiked with an adequate amount of the drug to give the desired final concentration.

For the voltammetric studies, the test solutions constituted by urine samples ten-fold diluted with the supporting electrolyte ( $\mathrm{pH} \mathrm{1/4} \mathrm{8.7)} \mathrm{were} \mathrm{purged} \mathrm{with} \mathrm{nitrogen} \mathrm{(99.99 \%} \mathrm{from} \mathrm{LINDE} \mathrm{Portugal)} \mathrm{for} 15$ min, then the gas stream was directed over the solution surface. The preconcentra- tion was accomplished in quiescent solutions at the optimal potential of $-1.00 \mathrm{~V}$ during a deposition time of $10 \mathrm{~s}$. Following the cathodic poten- tial scan, a conditioning potential of $-2.00 \mathrm{~V}$ was applied to the MFM during $30 \mathrm{~s}$. The square-wave parameters used (except where otherwise stated) were a frequency of $100 \mathrm{~Hz}$, an amplitude of $20 \mathrm{mV}$ and a staircase of $5 \mathrm{mV}$. The quantifications were achieved by the standard additions method.

\section{RESULTS AND DISCUSSION}

In order to study the adsorptive behavior of $\mathrm{V}$ in urine, a series of optimization studies was carried out. Several parameters were investi- gated, namely, reaction irreversibility, deposition potential, reproducibil- ity, $\mathrm{pH}$, deposition time, frequency, amplitude, staircase step, linearity range, and detection limit. Recovery experiments were performed to evaluate the accuracy of the developed electrochemical method.

\section{Adsorption and Irreversibility}

Figure 1 illustrates two successive cyclic voltammograms for

$19.7 \mathrm{mmol} \mathrm{L}^{-1}$ of $\mathrm{V}$ recorded at a scan rate of $100 \mathrm{mV} \mathrm{s}^{-1}$ after accumula- tion at $-1.00 \mathrm{~V}$ during 10 s. A cathodic peak, due to the reduction of the adsorbed drug, is observed at the first scan (dotted line) at ca. $-1.65 \mathrm{~V}$ and no anodic peak is detected. The short preconcentration time applied results in

a great enhancement of the peak intensity as compared with the 


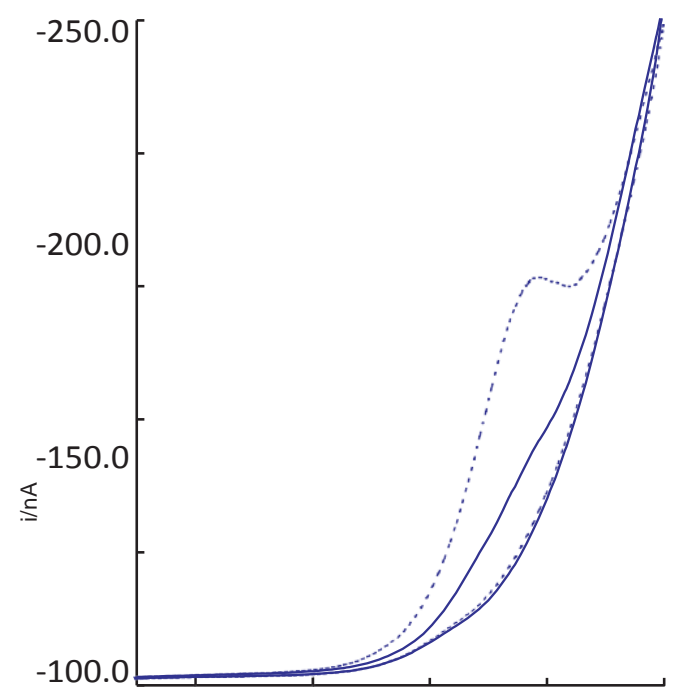

$-50.0$

0.0

$\begin{array}{lllll}-1.10 & - & - & - & -1.90 \\ & 1.3 & 1.5 & 1.7 & \\ 0 & 0 & 0 & \end{array}$

$\mathrm{E} / \mathrm{V}(v s . \mathrm{Ag} / \mathrm{AgCl})$

Figure 1. Successive (-first scan) cyclic voltammograms for a urine sample containing $19.7 \mathrm{mmol} \mathrm{L}^{-1}$ of venlafaxine and $1.25 \times 10^{-2}$ $\mathrm{mol} \mathrm{L}^{-1}$ borate buffer $\left(\mathrm{pH}^{1 / 4} 8.7\right)$ after $10 \mathrm{~s}$ deposition at $-1.00 \mathrm{~V}$. Scan rate: $100 \mathrm{mV} \mathrm{s}^{-1}$. No accumulation was performed before the second scan.

response obtained at the second scan performed without deposition (con- tinuous line). The scan rate was varied between $60 \mathrm{mV} \mathrm{s}^{-1}$ and $400 \mathrm{mV} \mathrm{s}^{-1}$ and it was observed that the cathodic peak current was linearly depen- dent on the scan rate $\left(i(n A) 1 / 4-22.0-0.106 \times\right.$ scan rate $\left.\left(\mathrm{mV} \mathrm{s}^{-1}\right) ; r^{1 / 4} 0.998 ; n 1 / 411\right)$. This relation proved that the reduction of $\mathrm{V}$ is con-trolled by adsorption of the reactant at the MFM. The absence of the anodic peak indicated that the reduction is irreversible which was confirmed by the linear relationship obtained between the peak potential and the logarithm of the scan rate $(E$ (V) $1 / 4-1.48-0.0867 \times \log$ (scan rate); $r^{1 / 4} 0.997 ; n 1 \frac{11}{11}$; scan rate varied between $60 \mathrm{mV} \mathrm{s}^{-1}-400 \mathrm{mV} \mathrm{s}^{-1}$ ).

Deposition Potential and Reproducibility

The effect of the preconcentration potential on the peak height was evaluated by ranging the potential 
from $-0.30 \mathrm{~V}$ to $-2.00 \mathrm{~V}$. It is evident from the data plotted in Fig. 2 that the highest peak current was reached 


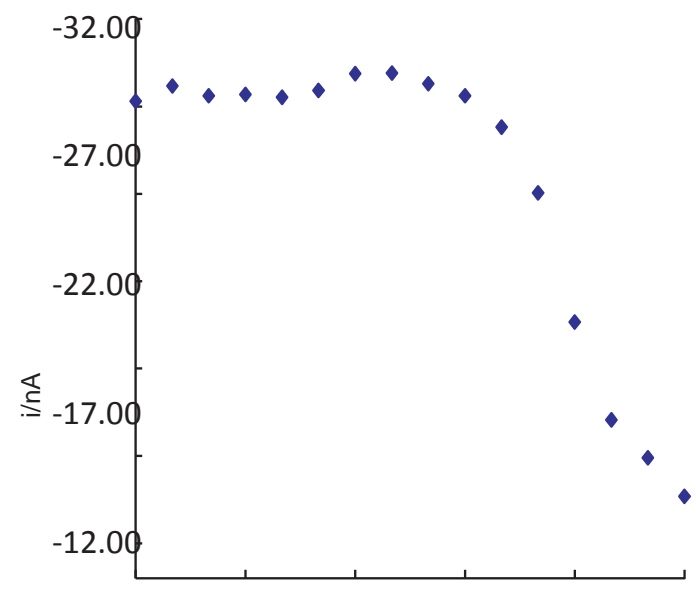

$-7.00$

$-2.00$

\begin{tabular}{cccccc}
-0.30 & - & - & - & - & -1.80 \\
& 0.6 & 0.9 & 1.2 & 1.5 & \\
0 & 0 & 0 & 0 \\
\multicolumn{5}{c}{ Deposition potential/V } \\
(vs. Ag/AgCl)
\end{tabular}

Figure 2. Effect of the deposition potential on the venlafaxine peak current in a urine sample containing $19.7 \mathrm{mmol} \mathrm{L}^{-1}$ of venlafaxine and $1.25 \mathrm{x}$

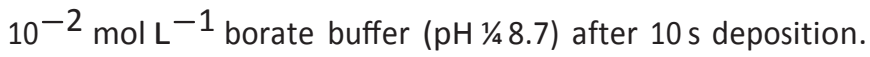

using $-1.00 \mathrm{~V}$ as deposition potential (no peak was detected using the deposition potential at $-1.90 \mathrm{~V}$ and $-2.00 \mathrm{~V}$ ).

To reduce the fouling of the MFM surface due to adsorption of the products of reaction and to enhance the reproducibility, a conditioning potential of $-2.00 \mathrm{~V}$ was selected. This cleaning step was always performed, during $30 \mathrm{~s}$, before each new scan.

In order to investigate the reproducibility of the response of the MFM in urine samples using the conditioning step, scans of the same solution were run during ca. $1 \mathrm{~h}$. A RSD value of $4.05 \%$ ($34.6 \pm 1.4 \mathrm{nA}$ ) was obtained for the peak height measurements.

$\mathrm{pH}$

The main factor influencing $\mathrm{V}$ peak shape and peak height was the solution $\mathrm{pH}$. The marked $\mathrm{pH}$ effect was evaluated over the $\mathrm{pH}$ range 4.1-9.9 (in increments of ca. 0.5) using Britton-Robinson buffer. Figure 3 shows the main results. From the analysis of this plot, the optimum pH appears to be between ca. 8.5 (Fig. 3, curve b) and 9.0 (Fig. 3 curve c). Acidic and neutral pH values rendered the baseline 

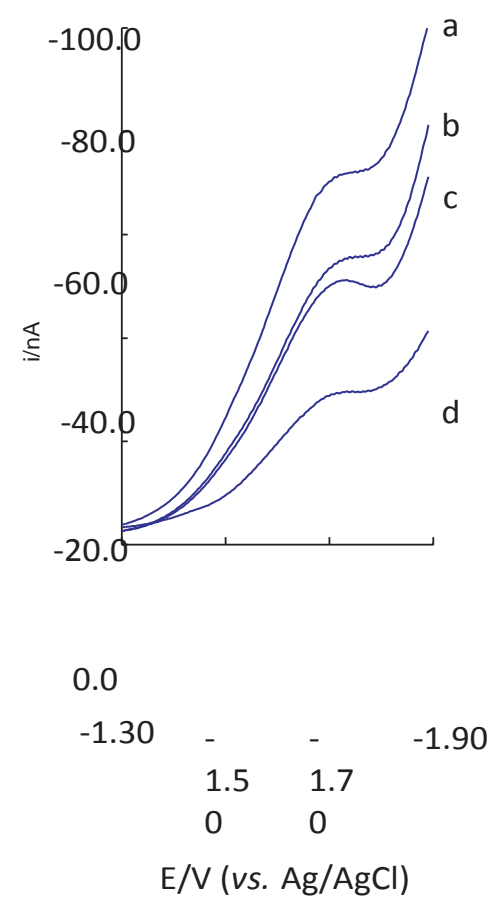

Figure 3. Effect of varying $\mathrm{pH}$ on the adsorptive stripping peak height in a urine sample containing $9.86 \mathrm{mmol} \mathrm{L}^{-1}$ of venlafaxine and BrittonRobinson buffer. Deposition: $10 \mathrm{~s}$ at $-1.00 \mathrm{~V}$.; (a) $\mathrm{pH} 1 / 44.1$; (b) $\mathrm{pH} 1 / 4$ 8.5; (c) $\mathrm{pH}^{1} 1 / 49.0$; $\quad$ (d) $\mathrm{pH}^{1} 1 / 49.9$.

slope so high that the peak was not well-defined and current measure- ments were difficult. pH values higher than ca. 9.0 provoked a decrease in peak current.

For selecting the optimal $\mathrm{pH}$, another assay was performed (not shown) but this time a smaller $\mathrm{pH}$ range was chosen, i.e., between 8.1 and 9.0. The results obtained showed that, between ca. 8.6 and 8.9, the peak is better defined and current remained approximately constant. The choice of $\mathrm{pH} 1 / 48.7$ appeared to be adequate considering that at this value the current is almost unaffected by small variations of $\mathrm{pH}$. Borate buffer was selected as the supporting electrolyte since it is an effective buffer to fix $\mathrm{pH}$ at the optimal value and does not interfere with the analysis of $\mathrm{V}$ in urine.

No effect on the peak potential was observed on varying the $\mathrm{pH}$ from 4.1 to 9.9.

\section{Deposition Time}

The effect of the accumulation time (between 0 and $300 \mathrm{~s}$ ) was investigated in a urine sample containing $9.86 \mathrm{mmol} \mathrm{L}^{-1}$ of $\mathrm{V}$ and it was observed that the peak height increases linearly with the deposition time 
between 0 and $15 s\left(i(n A) 1 / 4-5.87-0.518 \times\right.$ deposition time $\left.(s) ; r \frac{1}{4} 0.998 ; n \frac{1}{4} 6\right)$ and then tended to reach a plateau, indicating that gradual saturation of the MFM occurred following a typical adsorption isotherm behavior. Obviously, as the determination of the limit of detection will show, the linear relationship between peak intensity and collection time may be extended in samples containing lower bulk concentrations of the drug. Accumulation curves obtained for urine samples also showed that maximum adsorption was reached with a shorter deposition time than in aqueous solution, probably owing to the presence of natural surfactants in urine, which competed for the adsorption sites of the MFM. In all analyses carried out, the maximum deposition time used was 30 s, i.e., experimental conditions that fall within the initial zone of the accumulation curves where the maximum peak current: deposition time: concentration ratios are attainable, were always applied.

Due to the inherent properties of microelectrodes, ${ }^{[9-10]}$ no forced

convection during the deposition step and no equilibration period before the cathodic scan were used.

Instrumental Parameters

Optimization of the square-wave parameters indicated that an ampli- tude of $20 \mathrm{mV}$, a staircase step of $5 \mathrm{mV}$ and a frequency of $100 \mathrm{~Hz}$ were the most suitable for $\mathrm{V}$ quantification in urine samples taking in consid- eration the peak definition (when smaller amplitudes were used the base- line became smoother and the peak shape was improved; high staircase step resulted in peak distortion), the sensitivity (the peak height increased sharply and linearly till $150 \mathrm{~Hz}$ : $i(n A) \quad 1 / 4-20.4-0.0767 \times$ frequency $(\mathrm{Hz}) ; r 1 \frac{1}{4} 0.999$; $n 1 / 415)$ and the speed of analysis. The high scan rate used, $500 \mathrm{mV} / \mathrm{s}$, promoted a good sensitivity probably due to the stronger nature of the drug adsorption when compared to the adsorptive properties of other surface-active compounds present in urine.

\section{Linearity Range, Detection Limit, Accuracy, and Precision}

A sample containing $1.27 \mathrm{mmol} \mathrm{L}^{-1}$ of $\mathrm{V}$ and the standard additions method were used to establish the linearity range (Figs. 4 and 5). With a $30 \mathrm{~s}$ deposition time, the peak height increased linearly $(i(n A)$ $\left.1 / 4-0.937-0.797 \times\left[\mathrm{V}\left(\mathrm{mmol} \mathrm{L}^{-1}\right)\right] ; \quad r^{1 / 4} 0.9997 ; n 1 / 48\right)$ up to the seventh standard addition of $\mathrm{V}$ (each of $3.29 \mathrm{mmol} \mathrm{L}^{-1}$ ) that corresponded to a final 


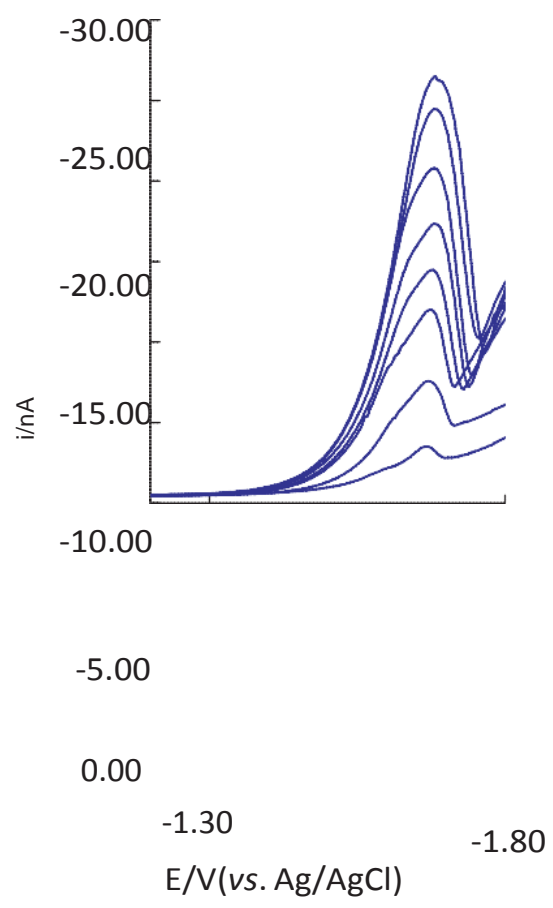

Figure 4. Voltammograms obtained after 7 successive standard additions in an urine sample containing $1.27 \mathrm{mmol} \mathrm{L}^{-1}$ of venlafaxine and $1.25 \times$ $10^{-2} \mathrm{~mol} \mathrm{~L}^{-1}$ borate buffer $\left(\mathrm{pH}^{1 / 4}\right.$ 8.7) for determining the linearity range. $30 \mathrm{~s}$ deposition at

$-1.00 \mathrm{~V}$.

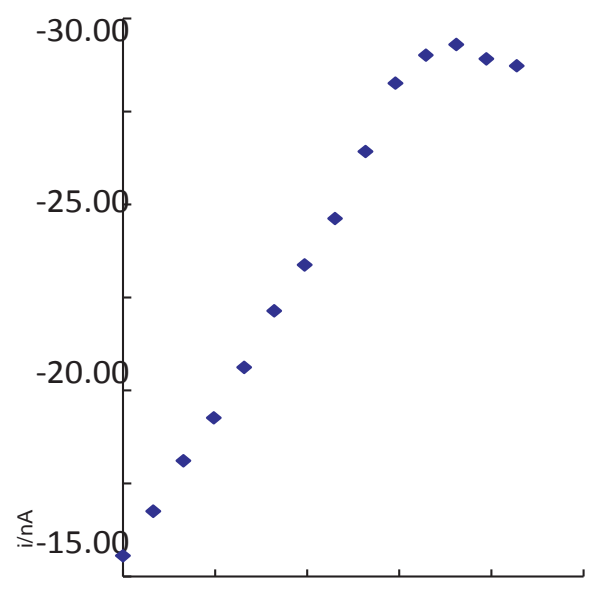




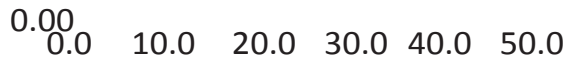 \\ [Venl.]/(x10-6 $\left.\mathrm{mol} \mathrm{L}^{-1}\right)$}

Figure 5. Standard additions method in a urine sample containing 1.27 $\mathrm{mmol} \mathrm{L}^{-1}$ and $1.25 \times 10^{-2} \mathrm{~mol} \mathrm{~L}^{-1}$ borate buffer $\left(\mathrm{pH}^{1 / 4}\right.$ 8.7) for determining the linearity range. Peak current vs. added venlafaxine concentration. $30 \mathrm{~s}$ deposition at $-1.00 \mathrm{~V}$. 
Table 1. Results of the determination of venlafaxine in three spiked urine samples. RSD: relative standard deviation; n: number of quantifications performed.

\begin{tabular}{lllll}
\hline $\begin{array}{l}\text { Amount } \\
\text { added }(\mathrm{mmol}\end{array}$ & $n$ & $\begin{array}{c}\text { Found } \\
\left(\mathrm{mmol} \mathrm{L}^{-}\right.\end{array}$ & $\begin{array}{c}\text { RSD } \\
(\%)\end{array}$ & $\begin{array}{l}\text { Bias } \\
(\%)\end{array}$ \\
\hline 4.93 & 3 & $5.12 \pm 0.013$ & 0.25 & $\mathrm{p3.9}$ \\
7.95 & 3 & $7.69 \pm 0.27$ & 3.5 & -3.3 \\
14.4 & 3 & $14.4 \pm 0.37$ & 2.6 & -1.8 \\
\hline
\end{tabular}

concentration of $24.3 \mathrm{mmol} \mathrm{L}^{-1}$ in the sample. When further standard additions were made, deviations from linearity became significant due to the saturation of the MFM (Fig. 5). The mean equation of the linear part of the plot was used to calculate the limit of detection (LOD), as recommended by IUPAC, ${ }^{[17]}$ and a value of $0.693 \mathrm{mmol} \mathrm{L}^{-1}$ was obtained.

The accuracy of $\mathrm{V}$ determination was tested by three recovery experiments doing three quantifications $(n)$ of the same urine sample (each quantification was performed by five standard additions of $1.64 \mathrm{mmol} \mathrm{L}^{-1}$ with three replicates at each concentration). The results obtained are presented in Table 1 . Bias less than $5 \%$ proved that the developed method is accurate at the concentration level studied and that the assays precision, expressed in terms of the relative standard deviation, is satisfactory $(0.25-3.5 \%)$.

\section{CONCLUSIONS}

While no previous data, at the knowledge of this research team, are available regarding the voltammetric quantification of $\mathrm{V}$ in biological fluids, the present work demonstrates that this can be successfully accom- plished, in urine, using a MFM and adsorptive stripping voltammetry. Interferences from organic compounds and, particularly, surface-active substances present in the biological matrix were minimized by various approaches to avoid performing an extraction step. A ten-fold dilution of urine samples was performed. The use of a MFM eliminated the need for convection by hydrodynamics during the deposition step and reduced the pre-concentration time: these factors are particularly advantageous for analysis of biological fluids since longer accumulation times and stirring of the solution enhance the diffusion of interfering large compounds which normally diffuse very slowly to the electrode surface in quiescent 
solutions. The standard additions method was applied. However, if $\mathrm{V}$ is to be analyzed in media with much higher content of organic matter (blood, serum, etc.) simple cleanup procedures (e.g., extraction or protein precipitation), common in the clinical laboratory, that may be coupled with the medium exchange procedure ${ }^{[18]}$ and higher dilutions may be required. The method proposed for the determination of $\mathrm{V}$ in urine sam- ples is comparable to most published chromatographic methods in what concerns the linearity range (D. R. Hicks et al. referred an analytical range of $0.319-31.9 \mathrm{mmol} \mathrm{L}^{-}$ 1[3]; M. Matoga et al. reported a linear response between $0.637 \mathrm{mmol} \mathrm{L}^{-1}$ and $12.7 \mathrm{mmol} \mathrm{L}^{-}$ $1[19]$; these groups did not presented LOD values and consequently no direct comparison is possible since the referred chromatographic methods employed laborious and complex extraction/preconcentration procedures lacking specificity. A separation step will be needed for improving the selectivity of the developed adsorptive stripping voltammetric procedure, e.g., for differentiating between the parent compound and its major metabolite (o-desmethylvenlafaxine). However, it is worthwhile to note that disposal of toxic or inflammable solvents is avoided (which is particularly important when daily routine analyses are made) and that the LOD obtained is adequate to detect as little as $1 \%$ of the $50 \mathrm{mg}$ pharmacolo- gical dose of $\mathrm{V}$ excreted over a $24 \mathrm{~h}$ period $^{[3]}$ being, consequently, appropriate to monitor therapeutic or toxic concentrations in urine.

\section{REFERENCES}

1. Schweizer, E.; Thielen, R.J.; Frazen, A. Expert opinion on investiga- tional drugs. 1997, 6, 6578.

2. Long, C.; Crifasi, J.; Maginn, D.; Graham, M.; Teas, S. J. Anal. Toxicol. 1997, 21, 166-169.

3. Hicks, D.R.; Russell, A.; Cavanugh, N.; Kraml, M. Therapeuting Drug Monitoring 1994, 16, 100-107.

4. Lima, J.L.F.C.; Loo, D.V.; Delerue-Matos, C.; Silva, A.S.R. II Farmaco. 1999, 54, 145-148.

5. Peng, J.; Jin, W. Anal. Chim. Acta. 1992, 264, 213-219.

6. Daniela, S.; Baldo, M.A.; Ugo, P.; Mazzocchin, G. Anal. Chim. Acta $1989,219,19-26$.

7. Vire, J.C.; Kauffmann, J.M.; Patriarche, G.J. J. Pharm. and Biomed. Anal. 1989, 7, $1323-$ 1335.

8. Berzas, J.J.; Flores, J.R.; Penalvo, G.C. Electroanalysis 2000, 12, 1059-1063. 
9. Tuno' n-Blanco, P.; Costa-Garci' a, A. Microelectrodes: new trends in their design and development of analytical applications. In Reviewson Analytical ChemistryEuroanalysis VIII; Littlejohn, D., Thorburn, D., Eds.; The Royal Society of Chemistry: 1994; 273-290.

10. Plecher, D. Why microelectrodes? In Microelectrodes: Theory and Applications;

Montenegro, M.I., Queiros, M.A., Daschbach, J.L.,Eds.; Kluwer Academic Publishers:

London/Boston/Dordrecht, NATO ASI Series, E197 1991, 3-14.

11. Morais, S.; Carvalho, G.S.; Sousa, J.P. Electroanalysis 1997, 9, 422-426.

12. Morais, S.; Carvalho, G.S.; Sousa, J.P. Electroanalysis 1997, 9, 791-795.

13. Morais, S.; Pereira, M.C. J. Trace Elements in Biology 2000, 14, 48-54.

14. Morais, S. Ph.D. Thesis, University of O’Porto, 1997.

15. Mongay, C.F.; Martí n, V.C. Talanta 1977, 24, 747-748.

16. Wightman, R.M.; Wipf, D.O. Voltammetry at ultramicroelectrodes. In Electroanalytical Chemistry; Bard, A.J., Ed.; Marcel Dekker, Inc.: New York and Basel, 1988; Vol. 15, 267353.

17. Miller, J.N. Analyst 1991, 116, 3-14.

18. Wang, J.; Bonakdar, M.; Morgan, C. Anal. Chem. 1986, 58, 1024-1028.

19. Matoga, M.; Pehourcq, F.; Titier, K.; Dumora, F.; Jarry, C. J. Chrom. B: Biomed. Sci. and Applications 2001, 760, 213-218. 